\title{
Fingolimod Modulates Peripheral Effector and Regulatory T Cells in MS Patients
}

\author{
Laura D. Serpero • Gilberto Filaci • Alessia Parodi • \\ Florinda Battaglia • Francesca Kalli • Davide Brogi • \\ Giovanni Luigi Mancardi • Antonio Uccelli • \\ Daniela Fenoglio
}

Received: 4 April 2013 / Accepted: 18 April 2013 /Published online: 7 May 2013

(C) The Author(s) 2013. This article is published with open access at Springerlink.com

\begin{abstract}
Multiple sclerosis (MS) is a complex neurological disease where, in genetically predisposed individuals, the unbalanced interplay between pathogenic and regulatory $\mathrm{T}$ cells will result in the progression of the autoimmune assault to neural antigens. Fingolimod (FTY720), an oral sphingosine 1-phosphate modulator recently approved for the treatment of MS, inhibits the egress of $T$ cells from lymph nodes acting specifically on naïve and memory $\mathrm{T}$ cells and sparing effector $\mathrm{T}$ cells. Here we characterized IL-17 and IFN $\gamma$ producing effector CD4 and CD8 positive T cells as well as CD4 positive $\mathrm{CD} 25^{\text {high }} \mathrm{CD} 127^{\text {low }}$ regulatory $\mathrm{T}$ cells in MS patients before and 1 month after treatment was started. We observed that fingolimod did not significantly affect the percentage of CCR6 and CD161 positive T cells in both CD4 and CD8 compartments. In contrast, it significantly reduced the levels of both CD4+ CCR6+ CD161+ and CD8+ CCR6+ CD161+ producing IFN $\gamma$ alone or in combination with IL-17. The
\end{abstract}

Antonio Uccelli and Daniela Fenoglio share equal credit for senior authorship.

L. D. Serpero · G. Filaci • A. Parodi · F. Battaglia • F. Kalli •

G. L. Mancardi $\cdot$ A. Uccelli $\cdot$ D. Fenoglio

Center of Excellence for Biomedical Research, University

of Genova, Viale Benedetto XV, 6,

16132 Genoa, Italy

L. D. Serpero • D. Brogi · G. L. Mancardi · A. Uccelli $(\bowtie)$

Department of Neuroscience, Rehabilitation, Ophthalmology,

Genetics, Maternal and Child Health (DINOGMI),

University of Genoa, Largo Daneo 3,

16132 Genoa, Italy

e-mail: auccelli@neurologia.unige.it

G. Filaci $\cdot$ D. Fenoglio

Department of Internal Medicine and Center of Excellence

for Biomedical Research, University of Genova,

Viale Benedetto XV, 6 ,

16132 Genoa, Italy percentage of IL-17 secreting cells in both subsets was affected by the treatment to a lesser extent. Finally, we observed that $\mathrm{CD} 4+\mathrm{CD} 25^{\text {high }} \mathrm{CD} 127^{\text {low }}$ regulatory $\mathrm{T}$ cells were decreased in MS patients compared to healthy controls and fingolimod significantly increased their frequencies. All together these findings demonstrate that fingolimod functionally modulates the ability of potentially pathogenic effector cells to produce relevant pro-inflammatory cytokines and increases the number of circulating regulatory $\mathrm{T}$ cells possibly contributing in restoring a balance between these populations.

Keywords Multiple sclerosis $\cdot$ T cells $\cdot$ IL-17 $\cdot$ IFN $\gamma \cdot$ S1P · Fingolimod

\section{Introduction}

Multiple sclerosis (MS) is a chronic, inflammatory disease of the central nervous system (CNS), driven by autoreactive lymphocytes resulting into an inflammatory cascade and subsequent degeneration of the neural tissue (Compston and Coles 2008). In healthy condition, the onset of an autoimmune response against the CNS is prevented by a tightly regulated balance between self-reacting immune cells and regulatory lymphocytes including both B and T cells. It is accepted that both Th1 and Th17 cells contribute to MS development (Lock et al. 2002; Brucklacher-Waldert et al. 2009; Goverman 2009). Although the implication of Th1 and Th17 CD4+ cells in the pathogenesis of MS has been largely investigated, several evidences support also the involvement of CD8+ T cells (Friese and Fugger 2009). Recently an IL-17-producing CD8+ T cells subset, named Tc17 has been described (Kondo et al. 2009) and reported to be present among cells infiltrating MS tissues (Tzartos et al. 2008; Huber et al. 2013). Moreover, an expansion of proinflammatory of $\mathrm{CD} 161{ }^{\mathrm{high}} \mathrm{CD} 8+\mathrm{T}$ cells 
was recently observed in MS subjects (Annibali et al. 2011). In the attempt of maintaining immune homeostasis, regulatory $\mathrm{T}$ cells (Treg) are supposed to control selfreacting $\mathrm{T}$ cells. In humans, CD4+ CD25+ Foxp3+ Tregs are defined by the low expression of the IL-7 receptor, CD127, (Liu et al. 2006) and high expression of CD39, an immunosuppressive ectonucleotidase reported to be poorly represented on circulating Treg cells of relapsingremitting MS patients (Borsellino et al. 2007).

Fingolimod (FTY720), a new sphingosine 1-phosphate (S1P) receptor modulator, is approved for the treatment of MS based on results from clinical trials in patients with relapsing remitting MS (Cohen et al. 2010; Kappos et al. 2010). It causes, in its phosphorylated form, internalization and degradation of cell membrane-expressed S1P receptor 1 , one of the five known S1P receptors, which is critical for $\mathrm{T}$ and $\mathrm{B}$ lymphocyte egress from secondary lymphoid organs and thymus. As consequence, lymphocytes retention in the lymph nodes is favored based on the prevalence of the signaling through CCR7, a receptor expressed by memory $\mathrm{T}$ cell (Cyster and Schwab 2012). Because of these features, fingolimod has been shown to significantly decrease the number of circulating $\mathrm{T}$ cells, interfering differently on naïve and memory $\mathrm{T}$ cell subsets (Mehling et al. 2008, 2010). In this study we evaluated the impact of fingolimod on peripheral blood $\mathrm{T}$ cell subsets relevant for MS pathogenesis with specific focus on the reciprocal relationship between the effector and regulatory arm of the immune response occurring in MS patients before and following FTY720 administration.

\section{Materials and methods}

Donors Peripheral venous blood was obtained with informed consent from ten relapsing remitting MS patients immediately before starting treatment with fingolimod and 1 month after therapy was started. MS patients were treated with fingolimod $0.5 \mathrm{mg}$ once daily, according to the current indication for MS treatment. Blood was also obtained from ten untreated healthy donors matched for age and sex with MS individuals. The number of patients contributing to each experiment is indicated in individual figure legends. The Ethical Committee of the IRCCS San Martino UniversityHospital, Genoa, Italy, approved this study.

Monoclonal antibodies (mAbs) For immunostaining and analysis by flow cytometry the following mAbs were used: allophycocianin (APC)-cyanin 7 conjugated anti-CD3, Horizon 500 conjugated anti-CD3, APC conjugated anti$\mathrm{CD} 25$, phycoerytrin (PE) conjugated anti-CCR6, PE conjugated anti-CD127, Pe-cyanin 7 conjugated anti-IFN $\gamma$, fluorescein isothiocynate (FITC) conjugated anti-CD39, Pe- cyanin 7 conjugated anti-CD4 (Becton Dickinson (BD) Biosciences); PerCP-cyanin 5.5 conjugated anti-CD8 (Biolegend); FITC conjugated anti-IL-17A (eBioscience); APC conjugated anti-CD161 (Miltenyi Biotec).

Generation of short-term $T$ cell lines and measurement of intracellular cytokines Peripheral blood mononuclear cells (PBMC) were isolated from heparinized venous blood by using density-gradient centrifugation over Ficoll-Hypaque (Biochrom). Short term $\mathrm{T}$ cell lines were generated by stimulation of PBMC $\left(3 \times 10^{6}\right.$ cells $)$ with anti-CD3 and anti-CD28 mAbs (BD) as described elsewhere (Fenoglio et al. 2011). Frequencies of cytokines producing cells from short-term $\mathrm{T}$ cell lines were analyzed following stimulation with phorbo-12-myristate-13-acetate (PMA $50 \mathrm{ng} / \mathrm{ml}$, Sigma) and ionomycine $(2 \mu \mathrm{g} / \mathrm{ml}$, Sigma $)$ as described elsewhere (Fenoglio et al. 2011). The cytokine profile of in vitro expanded T cells was evaluated using a FACSCanto II flow cytometer (BD Bioscience) by a FACSDiva software collecting 30000 viable T CD3+-gated events. Results were expressed as cytokine positive percentage of CD3+ $\mathrm{CD} 8+$ or $\mathrm{CD} 3+\mathrm{CD} 8$ - (for CD4) subsets in activated condition minus background staining, i.e. percentage of cytokinepositive $\mathrm{T}$ cells of not activated control.

Treg immunophenotyping Treg immunophenotyping was performed on $1 \times 10^{6} / 100 \mu \mathrm{l}$ PBMC incubated with fluorochrome-conjugated anti-CD3, -CD4, -CD25, -CD127, -CD39 antibodies. LIVE/DEAD (Invitrogen/Molecular Probes) was added to exclude dead cells. Samples were acquired and analyzed on FACSCanto II flow cytometer by FACSDiva software.

Statistical analyses Statistically significant differences between mean percentage of different $\mathrm{T}$ cell subsets observed in samples from MS patients and controls were analyzed by Mann-Whitney test for nonparametric values. Calculations were performed using GraphPad Prism, Version 4.00 software.

\section{Results}

Frequencies of CCR6- and CD161-positive cells are not affected by FTY720

As CD161 and CCR6 are considered reliable markers of Th17 cells, we analyzed CD161- and CCR6-positive T cells in the circulating CD4+ and CD8+ T cell pool before and 1 month after the first oral administration of FTY720. Evaluation was carried out in "ex-vivo" and "TCR-activated" $\mathrm{T}$ cells and compared to circulating $\mathrm{T}$ cells from healthy controls. The "ex vivo" frequencies of CCR6+ and CD161+ 
cells both in CD4+ and CD8+ T cells compartments of MS patients at baseline and after 1 month of therapy did not significantly differ from those measured in the peripheral blood from normal donors (Fig. 1a-d). In order to assess whether activation may lead to a significant change in the frequencies of these subsets, we performed the same analysis in short-term TCR-activated PBMC derived from MS individuals at similar time points. Accordingly no significant difference was observed in the frequencies of CCR6+ and CD161+ cells in CD4+ and CD8+ subsets regardless of the time PBMC were isolated before or 1 month after therapy was started (Fig. 1e-h). Thus, these data suggest that fingolimod does not significantly affect the peripheral blood representation of T cells expressing CCR6 and CD161.
FTY720 significantly reduces CD4+ T cell subsets producing pro-inflammatory cytokines

Next, we sought to evaluate the content of IFN $\gamma$ and IL-17 in these subpopulations following TCR activation. The percentage of IL-17 producing CD4+ T cells from MS patients after 1 month of treatment with fingolimod was significantly decreased compared to the levels observed before treatment ( $p=0.03$; Fig. $2 b$ ). In contrast, a less pronounced effect was observed on IFN $\gamma$ producing $\mathrm{T}$ cells (Fig. 2a). However, CD4+ T cells producing both cytokines were significantly diminished after therapy ( $p=$ 0.05; Fig. 2c). In the CCR6+ CD4+ subpopulation we observed a significant effect of treatment on the frequency of IFN $\gamma$ secreting cells ( $p=0.01$; Fig. $2 \mathrm{~d}$ ) while only a trend was detected for IL17 (Fig. 2e). However the combined analysis of both cytokines
Fig. 1 Frequencies of CCR6and CD161-positive cells in circulating and TCR-activated CD4+ and CD8+ T

lymphocytes. Ex vivo evaluation of CCR6- and CD161-positive fraction in CD4 (Panels a-b) and in CD8+ $T$ cells (Panels c-d) derived from PBMC of ten controls (HD) and ten MS patients at baseline $(M S t 0)$ and after FTY720 administration (MS t1). Percentage analysis of CCR6+ (Panel e) and CD161+ (Panel f) CD4+ T cells, CCR6+ (Panel g) and CD161+ (Panel h) $\mathrm{CD} 8+\mathrm{T}$ cells in short-term TCR-activated peripheral lymphocytes derived from ten MS patients at baseline $(t 0)$ and after FTY720 administration $(t 1)$
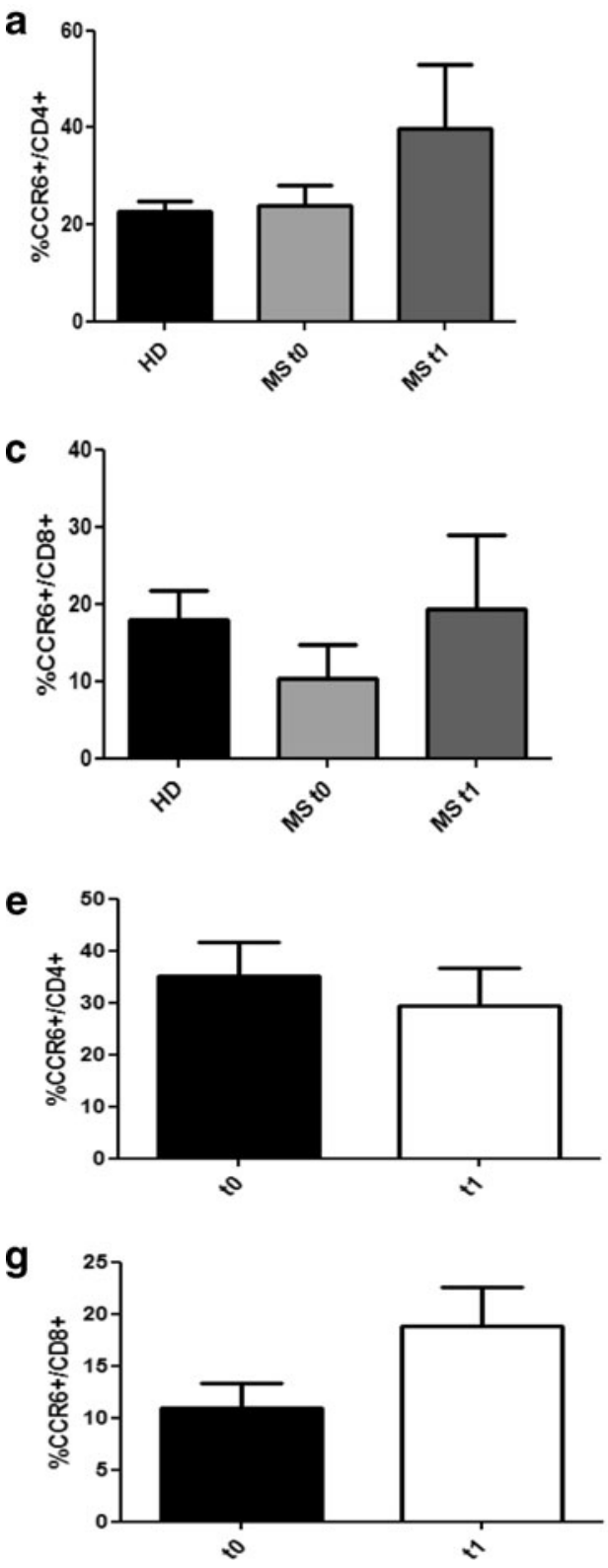
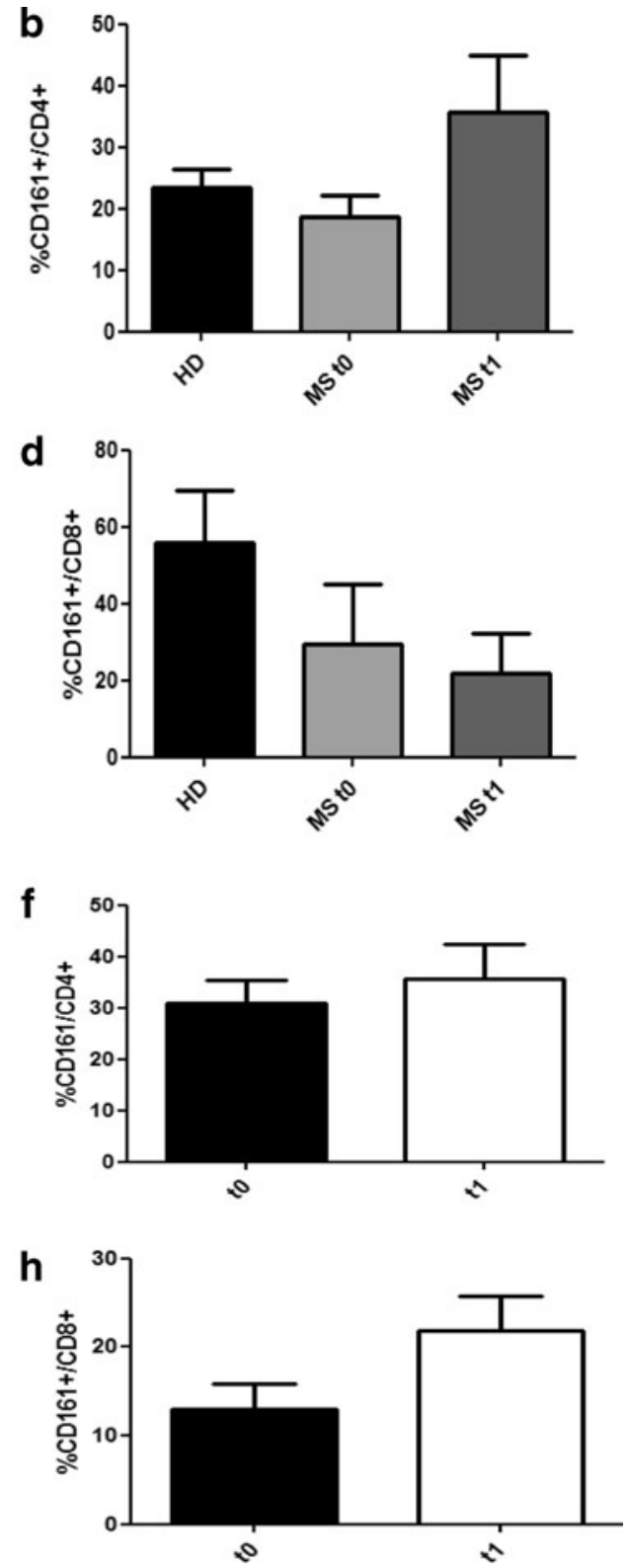
a

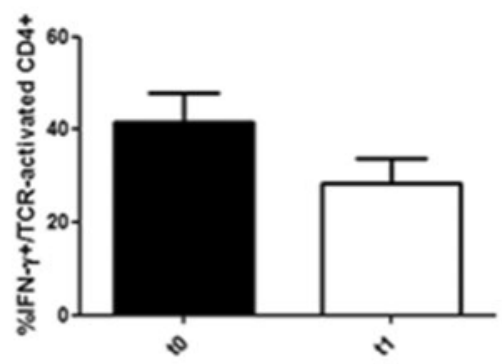

b

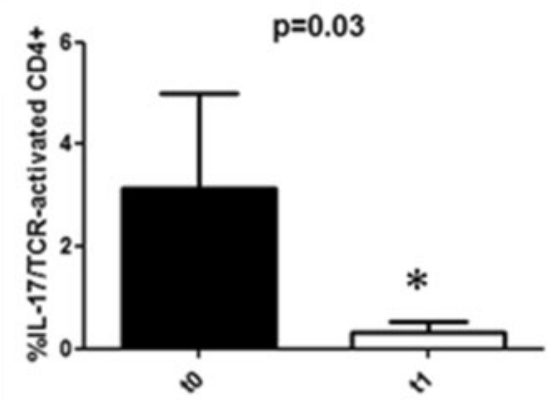

C

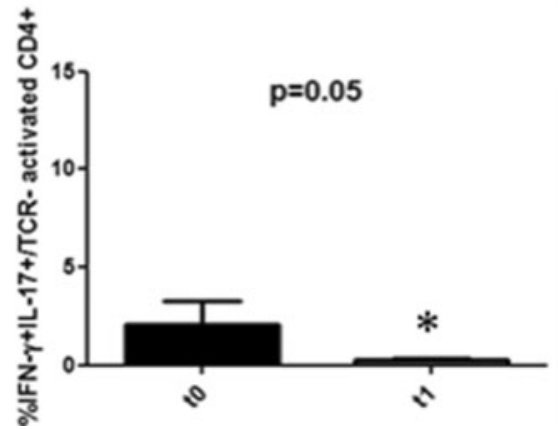

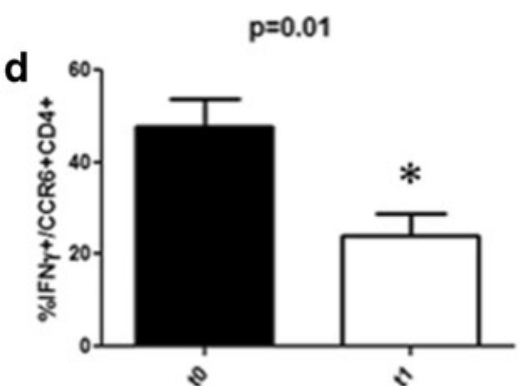

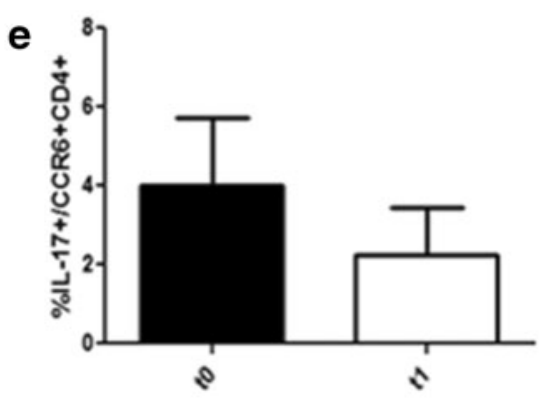

f

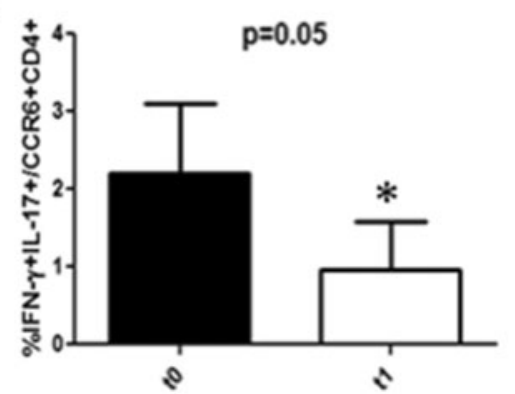

$\mathrm{p}=0.002$

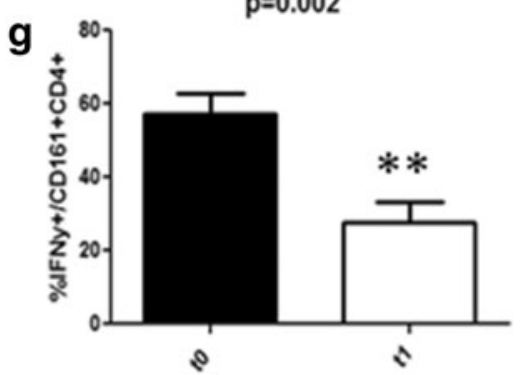

h

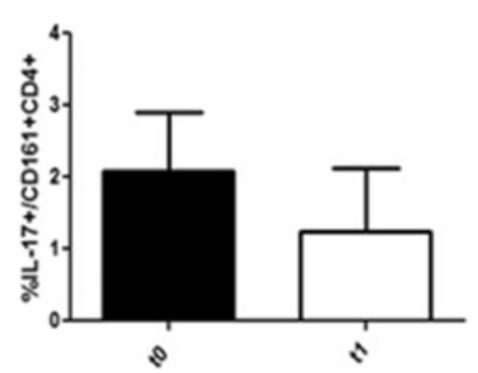

i

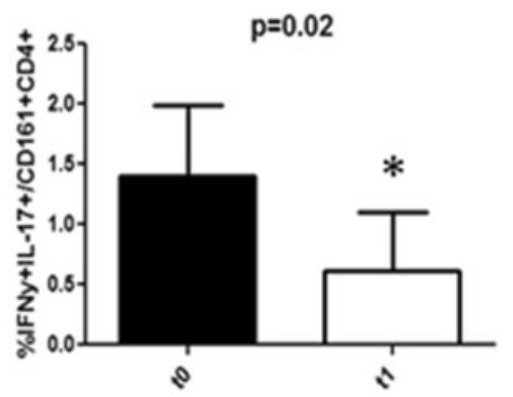

Fig. 2 Cytokine analysis of TCR-activated CD4+ T lymphocytes in MS patients at baseline $(t 0)$ and after FTY720 administration $(t 1)$. Comparison of the frequencies of IFN $\gamma$-, IL-17-single and IFN $\gamma$ and IL-17-double producing cells in TCR-expanded CD4+ T subset (Panels $\mathbf{a}-\mathbf{b}-\mathbf{c})$, in CCR6+ (Panels d-e-f) and in CD161+ (Panels g-h-i) TCRexpanded CD4 $+\mathrm{T}$ cell populations derived from ten MS patients at baseline $(t 0)$ and after FTY720 administration $(t 1)$ in CCR6+ CD4+ $\mathrm{T}$ cells demonstrated a significant reduction after 1 month of treatment ( $p=0.05$; Fig. 2f). Similar results were obtained when the CD161+CD4+ subset was analyzed, confirming that FTY720 significantly inhibited the percentage of IFN $\gamma$ but not IL17 producing cells compared to before treatment ( $p=0.002$; Fig. $2 \mathrm{~g}-\mathrm{h})$. Accordingly, IL-17- and IFN $\gamma$-producing cells were significantly decreased in CD161+ CD4+ T cells ( $p=0.02$; Fig. 2i). These results suggest that, in MS patients, treatment with fingolimod leads to a significant decrease of CCR6+ and CD161+ CD4+ producing both IFN $\gamma$ and IL-17.

Fingolimod decreases $\mathrm{CD} 8+\mathrm{T}$ cells producing IFN $\gamma$ and IL-17

Next, we sought to address whether administration of fingolimod could affect the number of IFN $\gamma$ and IL-17 producing cells within the $\mathrm{CD} 8+$ compartment. We observed a statistically significant drop in the percentage of IFN $\gamma$ producing cells ( $p=0.014$; Fig. 3a), whereas the reduction of $\mathrm{T}$ cells producing IL-17 alone or in combination with IFN $\gamma$ did not reach statistical significance (Fig. 3b and c). We detected a significant decrement of CCR6+ $\mathrm{CD} 8+\mathrm{T}$ cells producing IFN $\gamma$ alone or in combination with IL-17 in patients after 1 month of therapy ( $p=0.003$, Fig. $3 \mathrm{~d}$ and $p=0.009$, Fig. $3 \mathrm{f}$ respectively). The percentage of IL-17 producing cells in the CCR6+ CD8+ subset did not significantly differ among MS patients before and after FTY720 treatment (Fig. 3e). Also the number of CD161+CD8+ T cells producing IFN $\gamma$ alone or in combination with -IL17 remarkably dropped after 1 month of therapy compared to levels detected before fingolimod was started $(p=0.05$, Fig. $3 \mathrm{~g}$ and $p=0.03$, Fig. $3 \mathrm{i}$ respectively). The decrease in IL-17 producing CD161+ CD8+ T cells was not significant (Fig. 3h). Because it has been previously reported that 
a

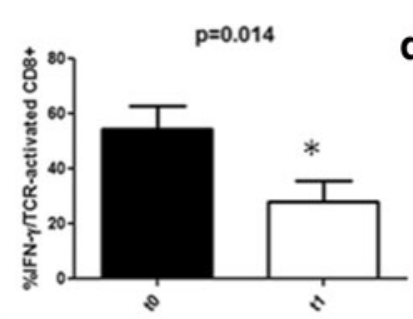

b

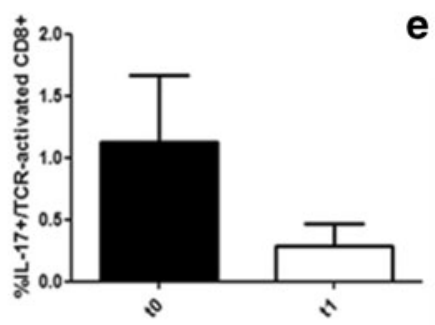

c

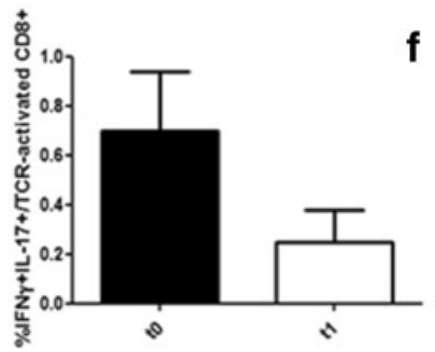

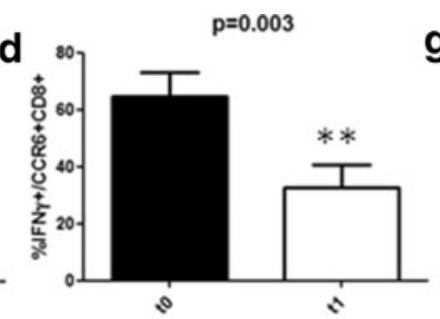

e

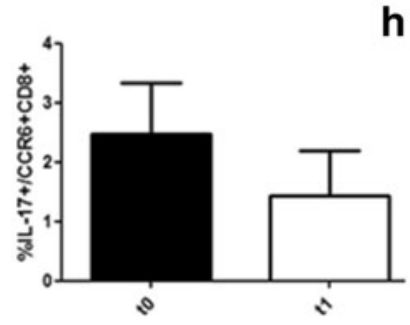

f

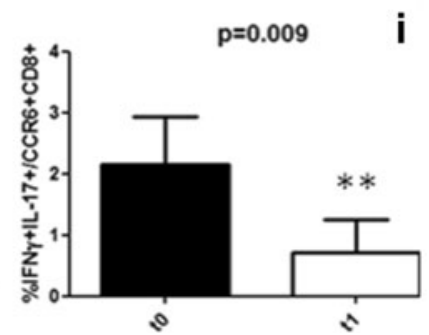

h
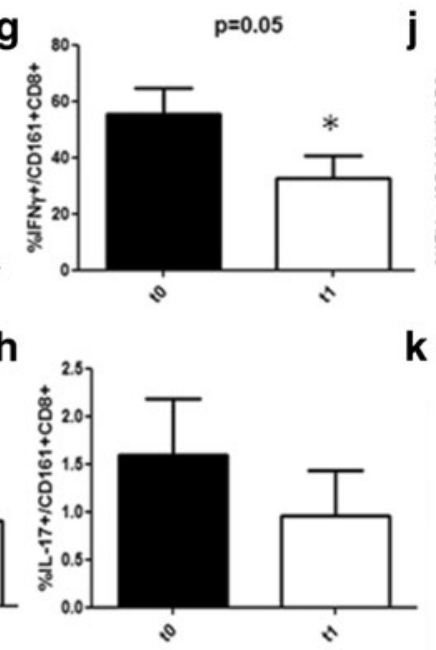

$\mathbf{k}$

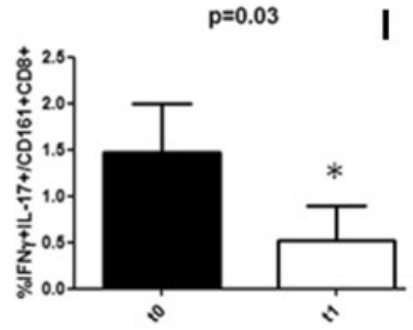

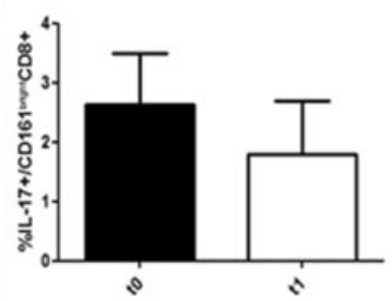
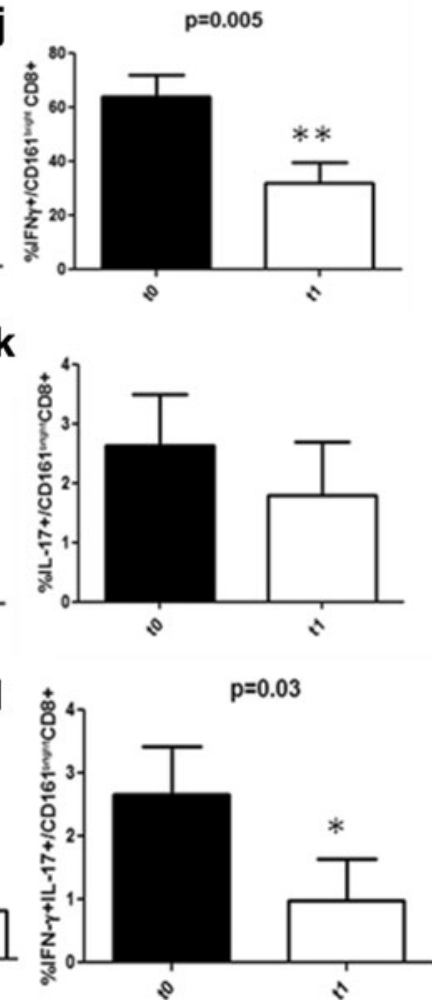

Fig. 3 Cytokine analysis of TCR-activated CD8+ T lymphocytes in MS patients at baseline $(t 0)$ and after FTY720 administration $(t 1)$. Comparison of the frequencies of IFN $\gamma$-, IL-17-single and IFN $\gamma$ and IL-17-double producing cells in TCR-activated CD8+ T subset (Panels a-b-c), in CCR6+ (Panels d-e-f), CD161+ (Panels $\mathbf{g}-\mathbf{h}-\mathbf{i})$ and CD161 ${ }^{\text {bright }}$ (Panels $\mathbf{j}-\mathbf{k}-\mathbf{l}$ ) of short-term TCR-activated CD8+ T cell populations derived from ten MS patients at baseline $(t 0)$ and after FTY720 administration $(t 1)$
CD161 $1^{\text {bright }} \mathrm{T}$ cells co-express CCR6 and are the major source of IL-17 and IFN $\gamma$ in the CD8 positive population (Annibali et al. 2011) we analyzed this subset in MS individuals before and after fingolimod therapy. The frequencies of $\mathrm{CD} 8+\mathrm{CD} 161^{\text {high }} \mathrm{CCR} 6+\mathrm{T}$ cells producing IFN $\gamma$ alone or in combination with IL-17 was significantly reduced in patients treated with fingolimod compared to levels detectable before starting the therapy $(p=0.005$; Fig. $3 \mathrm{j}$ and $p=0.03$ Fig. 31).

These findings prove that, similarly to what observed for CD4+ T cells, also levels of circulating CD8+ T cells expressing CD161 and CCR6 and producing IFN $\gamma$ and, to a lesser extent, IL-17 are decreased 1 month after fingolimod was started.

Treg are increased in MS patients treated with FTY720

Next we analyzed the possibility that fingolimod may have an impact on CD4+ Tregs as defined by the expression of CD25 and CD127 on T cells in the peripheral blood of MS patients before and after therapy was started. Furthermore, the percentage of Tregs in healthy controls was also compared to MS individuals at both time points. The comparison between controls and MS patients at baseline showed a statistically significant decrease of this subset in the peripheral blood of untreated MS subjects ( $p$ $=0.005$; Fig. 4a). Noteworthy, we detected a statistically significant increment ( $p=0.014$; Fig. 4 a) of circulating Treg cells in MS patients after fingolimod treatment, back to levels similar to those observed in healthy controls. We observed also a remarkable reduction of expression levels of CD39 on CD4+ $\mathrm{CD} 25^{\text {high }} \mathrm{CD} 127^{\text {low }} \mathrm{T}$ cells in MS patients at baseline compared to controls ( $p=0.006$; Fig. $4 \mathrm{~b}$ ). CD39 expression was increased on Tregs 1 month after fingolimod was started (Fig. 4b). Frequencies of CD39 expressing CD8+ were not changed in MS patients between the two time points (data not shown). These findings confirm that Treg levels are decreased in MS subjects and suggest that fingolimod can restore their levels similar to those detected in healthy controls.

\section{Discussion}

Multiple sclerosis is an autoimmune disease where $\mathrm{T}$ cells probably recognizing myelin antigens are playing a major role (Goverman 2009). Autoimmune diseases may develop from an unbalanced relationship between effector and regulatory arms of the immune system (Wing and Sakaguchi 2010; Fenoglio et al. 2011). Current evidence acquired from both 

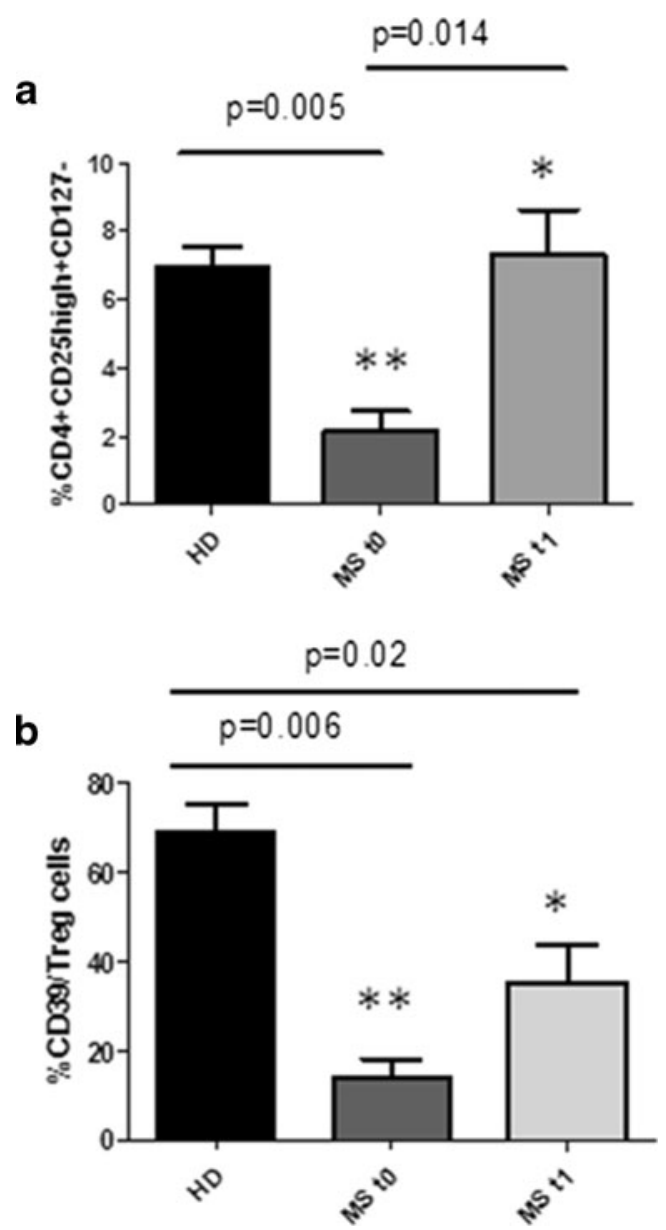

Fig. 4 Analysis of Treg frequencies in the peripheral blood of MS and healthy individuals. Comparison of the frequency of CD4+ $\mathrm{CD} 25^{\text {high }} \mathrm{CD} 127$ - (Panel a) and $\mathrm{CD} 39+\mathrm{CD} 25^{\text {high }} \mathrm{CD} 127^{\text {low }} \mathrm{CD} 4+$ circulating Treg cells from ten healthy donors and ten MS patients at baseline and after FTY720 therapy

animal models and MS individuals suggests the involvement of CD4 positive T helper cells producing IFN $\gamma$ and IL-17, characteristics of a Th1 and Th17 phenotype (Lock et al. 2002; Brucklacher-Waldert et al. 2009). However, T helper subsets are highly heterogeneous as demonstrated by the ability of $\mathrm{T}$ cells to often coproduce IL-17 and IFN $\gamma$ (Kebir et al. 2009; Cosmi et al. 2011). A higher level of complexity is provided by the involvement of CD8 positive T cells in MS pathogenesis (Friese and Fugger 2009). A better elucidation of such intricate picture has been favored by the recent identification of markers, such as the NK receptor CD161, specifically associated with Th17 profile (Cosmi et al. 2008). Th17 cells may acquire a nonclassical Th1 phenotype upon inflammatory cues as depicted by the expression of the Th17 marker CD161 (Cosmi et al. 2008). In addition, recent reports suggest a role in MS pathogenesis for IL-17-producing CD8+ T cells (Tc17) (Tzartos et al. 2008; Huber et al. 2013), based on the observation that CD8+ T cells detected in the CNS and cerebrospinal fluid of MS individuals produce IL-17. A pathogenic role for $\mathrm{CD} 8+\mathrm{T}$ cells is further supported by the observation that $\mathrm{CD} 161{ }^{\text {high }} \mathrm{CD} 8+\mathrm{T}$ cells are expanded in the peripheral blood and display proinflammatory features including the ability to produce IL-17 (Annibali et al. 2011). Th17 cells also express high levels of CCR6, a receptor involved in the entry of pathogenic $\mathrm{T}$ cells into the CNS (Reboldi et al. 2009). In this study we analysed the impact of fingolimod, a new oral drug approved for the treatment of relapsing remitting MS, on classical and non-classical Th17 subsets relevant for MS pathogenesis. FTY720 has been previously demonstrated to significantly decrease the number of circulating CD4+ and, to a lesser extent, $\mathrm{CD} 8+\mathrm{T}$ cells, affecting mainly naïve and central memory $\mathrm{T}$ cells, while sparing CCR7- effector memory $\mathrm{T}$ cells, possibly involved in the efficient control of microbial infections observed in treated patients (Mehling et al. 2008). FTY720 significantly decreased peripheral blood levels of IL-17 producing $\mathrm{T}$ cells, which were demonstrated to reside mainly in the CCR4+ CCR6+ CD4+, thus supporting their, drug induced, retention in the secondary lymphoid organs (Mehling et al. 2010). In contrast with the latter study we demonstrated that fingolimod modestly affects the ex-vivo relative frequencies of CCR6+ CD161+ T cells both in the circulating CD4 and CD8 positive compartments of MS patients when compared to levels observed before therapy was started. Similar results were observed when these subsets were evaluated following short term in vitro stimulation suggesting that $\mathrm{T}$ cell activation, in fingolimod-treated patients, does not result in a significant change of these subpopulations. However, in agreement with Mehling and collaborators (Mehling et al. 2010), we observed that fingolimod administration resulted in a significant change of the frequencies of CD4 positive T cells producing IL-17 alone or in combination with IFN $\gamma$. In the CD8 positive T cells, FTY720 affected mainly the IFN $\gamma$-producing subset. Accordingly, when the phenotype of potentially pathogenic $T$ cells was further dissected, we observed that treatment decreased frequencies of CCR6 + and CD161+ T cells producing IL-17 in combination with IFN $\gamma$ or IFN $\gamma$ alone both in the $\mathrm{CD} 4+$ and in the $\mathrm{CD} 8+$ compartments. In particular, fingolimod significantly reduced levels of CD8+ CD161 ${ }^{\text {high }} \mathrm{CCR} 6+\mathrm{T}$ cells producing $\mathrm{IFN} \gamma$ alone or in combination with IL-17, a subset of CD8 positive T cells endowed by a remarkable pathogenic potential in MS (Annibali et al. 2011). These results further confirm that fingolimod appears to affect significantly CD4+ Th17 cells but also IFN $\gamma$ producing Th17 cells, a non-classical Th1/Th17 subpopulation, which is dynamically generated from classical Th17 cells under inflammatory condition (Annunziato et al. 2012). The preferred effect of fingolimod on CCR6+ CD161+ IFN $\gamma$ and IL-17 co-producing T cells might be explained by the inability of Th17 cells to proliferate upon TCR stimulation under inflammatory conditions because of reduced responsiveness to IL2 and impairment of $R O R C$-dependent pathways that lead to IL2 
production and cell proliferation resulting in a limited Th17 cells expansion at sites of inflammation (Santarlasci et al. 2012). In addition, these findings further support a selective effect of fingolimod on different $\mathrm{T}$ cell populations in MS individuals (Mehling et al. 2008, 2010), probably based on its ability to modulate S1PR1 on lymphocytes and therefore controlling their egress from lymphoid organs (Cyster and Schwab 2012). Of note, we observed also a statistically significant reduction of the frequencies of $\mathrm{CD} 4+\mathrm{CD} 25^{\text {high }} \mathrm{CD} 127^{\text {low }} \mathrm{T}$ cells in MS subjects naïve of therapy compared to controls. An impairment of Treg functions has been described in MS patients, which may underlie the compromised control of auto-reactive cells (Viglietta et al. 2004). Interestingly, the frequency of CD4+ $\mathrm{CD} 25^{\text {high }} \mathrm{CD} 127^{\text {low }} \mathrm{T}$ cells was significantly increased close to levels observed in controls 1 month after fingolimod was started. These results are in line with the recent report that CD127 polymorphisms can influence the frequency of circulating Treg in MS patients (Broux et al. 2010). Accordingly, we detected a drastic decrease in the percentage of CD39 expressing CD4+ $\mathrm{CD} 25^{\text {high }} \mathrm{CD} 127^{\text {low }}$ Tregs in MS patients compared to controls, which was significantly increased after FTY720 was started. These results are of remarkable importance as it has been suggested that CD39, an ectoenzyme with immunosuppressive features due to its involvement in ATP degradation, plays a major role in Treg activity leading to defective Tregs functions in CD4+ (Borsellino et al. 2007) and CD8+ subsets (Parodi et al. 2013). Therefore fingolimod increases the circulating levels of CD39-expressing Tregs consistent with the capability to restore Treg homeostasis and functions in MS patients. Taken together these data suggest a double beneficial role of fingolimod in negatively modulating inflammatory $\mathrm{T}$ cell circulation and/or activation and restoring Treg homeostasis. Based on this scenario, the analysis of frequencies of peripheral effector and regulatory $\mathrm{T}$ cell populations and their mutual balance, is of particular interest for the assessment of the mechanisms of action of immunomodulatory drugs relevant to MS treatment.

Disclosure AU and GLM received honoraria to act as advisor or speaker from BiogenIdec, Novartis, Merck Serono, Teva, Sanofi-Aventis, BayerSchering, AU also acted as advisor for Roche and Allergan. AU and GLM received financial support for research, not related to the study described in this manuscript from Merck Serono, BiogenIdec and Novartis.

Open Access This article is distributed under the terms of the Creative Commons Attribution License which permits any use, distribution, and reproduction in any medium, provided the original author(s) and the source are credited.

\section{References}

Annibali V, Ristori G, Angelini DF, Serafini B, Mechelli R, Cannoni S, Romano S, Paolillo A, Abderrahim H, Diamantini A, Borsellino G, Aloisi F, Battistini L, Salvetti M (2011) CD161(high)CD8+ T cells bear pathogenetic potential in multiple sclerosis. Brain 134:542-554
Annunziato F, Cosmi L, Liotta F, Maggi E, Romagnani S (2012) Defining the human T helper 17 cell phenotype. Trends Immunol 33:505-512

Borsellino G, Kleinewietfeld M, Di Mitri D, Sternjak A, Diamantini A, Giometto R, Hopner S, Centonze D, Bernardi G, Dell'Acqua ML, Rossini PM, Battistini L, Rotzschke O, Falk K (2007) Expression of ectonucleotidase CD39 by Foxp3+ Treg cells: hydrolysis of extracellular ATP and immune suppression. Blood 110:1225-1232

Broux B, Hellings N, Venken K, Rummens JL, Hensen K, Van Wijmeersch B, Stinissen P (2010) Haplotype 4 of the multiple sclerosis-associated interleukin-7 receptor alpha gene influences the frequency of recent thymic emigrants. Genes Immun 11:326-333

Brucklacher-Waldert V, Stuerner K, Kolster M, Wolthausen J, Tolosa E (2009) Phenotypical and functional characterization of T helper 17 cells in multiple sclerosis. Brain 132:3329-3341

Cohen JA, Barkhof F, Comi G, Hartung HP, Khatri BO, Montalban X, Pelletier J, Capra R, Gallo P, Izquierdo G, Tiel-Wilck K, de Vera A, Jin J, Stites T, Wu S, Aradhye S, Kappos L, Group TS (2010) Oral fingolimod or intramuscular interferon for relapsing multiple sclerosis. N Engl J Med 362:402-415

Compston A, Coles A (2008) Multiple sclerosis. Lancet 372:15021517

Cosmi L, De Palma R, Santarlasci V, Maggi L, Capone M, Frosali F, Rodolico G, Querci V, Abbate G, Angeli R, Berrino L, Fambrini M, Caproni M, Tonelli F, Lazzeri E, Parronchi P, Liotta F, Maggi E, Romagnani S, Annunziato F (2008) Human interleukin 17producing cells originate from a CD161+ CD4+ T cell precursor. J Exp Med 205:1903-1916

Cosmi L, Cimaz R, Maggi L, Santarlasci V, Capone M, Borriello F, Frosali F, Querci V, Simonini G, Barra G, Piccinni MP, Liotta F, De Palma R, Maggi E, Romagnani S, Annunziato F (2011) Evidence of the transient nature of the Th17 phenotype of CD4+ CD161+ T cells in the synovial fluid of patients with juvenile idiopathic arthritis. Arthritis Rheum 63:2504-2515

Cyster JG, Schwab SR (2012) Sphingosine-1-phosphate and lymphocyte egress from lymphoid organs. Annu Rev Immunol 30:69-94

Fenoglio D, Battaglia F, Parodi A, Stringara S, Negrini S, Panico N, Rizzi M, Kalli F, Conteduca G, Ghio M, De Palma R, Indiveri F, Filaci G (2011) Alteration of Th17 and Treg cell subpopulations co-exist in patients affected with systemic sclerosis. Clin Immunol 139:249-257

Friese MA, Fugger L (2009) Pathogenic CD8(+) T cells in multiple sclerosis. Ann Neurol 66:132-141

Goverman J (2009) Autoimmune T cell responses in the central nervous system. Nat Rev Immunol 9:393-407

Huber M, Heink S, Pagenstecher A, Reinhard K, Ritter J, Visekruna A, Guralnik A, Bollig N, Jeltsch K, Heinemann C, Wittmann E, Buch T, Prazeres da Costa O, Brustle A, Brenner D, Mak TW, Mittrucker HW, Tackenberg B, Kamradt T, Lohoff M (2013) IL17A secretion by CD8+ T cells supports Th17-mediated autoimmune encephalomyelitis. J Clin Investig 123:247-260

Kappos L, Radue EW, O’Connor P, Polman C, Hohlfeld R, Calabresi P, Selmaj K, Agoropoulou C, Leyk M, Zhang-Auberson L, Burtin P, Group FS (2010) A placebo-controlled trial of oral fingolimod in relapsing multiple sclerosis. N Engl J Med 362:387-401

Kebir H, Ifergan I, Alvarez JI, Bernard M, Poirier J, Arbour N, Duquette P, Prat A (2009) Preferential recruitment of interferongamma-expressing TH17 cells in multiple sclerosis. Ann Neurol 66:390-402

Kondo T, Takata H, Matsuki F, Takiguchi M (2009) Cutting edge: Phenotypic characterization and differentiation of human CD8+ T cells producing IL-17. J Immunol 182:1794-1798

Liu W, Putnam AL, Xu-Yu Z, Szot GL, Lee MR, Zhu S, Gottlieb PA, Kapranov P, Gingeras TR, Fazekas de St Groth B, Clayberger C, Soper DM, Ziegler SF, Bluestone JA (2006) CD127 expression inversely correlates with FoxP3 and suppressive function of human CD4+ T reg cells. J Exp Med 203:1701-1711 
Lock C, Hermans G, Pedotti R, Brendolan A, Schadt E, Garren H, Langer-Gould A, Strober S, Cannella B, Allard J, Klonowski P, Austin A, Lad N, Kaminski N, Galli SJ, Oksenberg JR, Raine CS, Heller R, Steinman L (2002) Gene-microarray analysis of multiple sclerosis lesions yields new targets validated in autoimmune encephalomyelitis. Nat Med 8:500-508

Mehling M, Brinkmann V, Antel J, Bar-Or A, Goebels N, Vedrine C, Kristofic C, Kuhle J, Lindberg RL, Kappos L (2008) FTY720 therapy exerts differential effects on $\mathrm{T}$ cell subsets in multiple sclerosis. Neurology 71:1261-1267

Mehling M, Lindberg R, Raulf F, Kuhle J, Hess C, Kappos L, Brinkmann V (2010) Th17 central memory T cells are reduced by FTY720 in patients with multiple sclerosis. Neurology 75:403-410

Parodi A, Battaglia F, Kalli F, Ferrera F, Conteduca G, Tardito S, Stringara S, Ivaldi F, Negrini S, Borgonovo G, Simonato A, Traverso P, Carmignani G, Fenoglio D, Filaci G (2013) CD39 is highly involved in mediating the suppression activity of tumorinfiltrating CD8 $+\mathrm{T}$ regulatory lymphocytes. Cancer Immunol Immunother. 62:851-862
Reboldi A, Coisne C, Baumjohann D, Benvenuto F, Bottinelli D, Lira S, Uccelli A, Lanzavecchia A, Engelhardt B, Sallusto F (2009) C$\mathrm{C}$ chemokine receptor 6-regulated entry of TH-17 cells into the CNS through the choroid plexus is required for the initiation of EAE. Nat Immunol 10:514-523

Santarlasci V, Maggi L, Capone M, Querci V, Beltrame L, Cavalieri D, D'Aiuto E, Cimaz R, Nebbioso A, Liotta F, De Palma R, Maggi E, Cosmi L, Romagnani S, Annunziato F (2012) Rarity of human T helper 17 cells is due to retinoic acid orphan receptor-dependent mechanisms that limit their expansion. Immunity 36:201-214

Tzartos JS, Friese MA, Craner MJ, Palace J, Newcombe J, Esiri MM, Fugger L (2008) Interleukin-17 production in central nervous system-infiltrating $\mathrm{T}$ cells and glial cells is associated with active disease in multiple sclerosis. Am J Pathol 172:146-155

Viglietta V, Baecher-Allan C, Weiner HL, Hafler DA (2004) Loss of functional suppression by CD4+ CD25+ regulatory $\mathrm{T}$ cells in patients with multiple sclerosis. J Exp Med 199:971-979

Wing K, Sakaguchi S (2010) Regulatory T cells exert checks and balances on self tolerance and autoimmunity. Nat Immunol 11:7-13 